
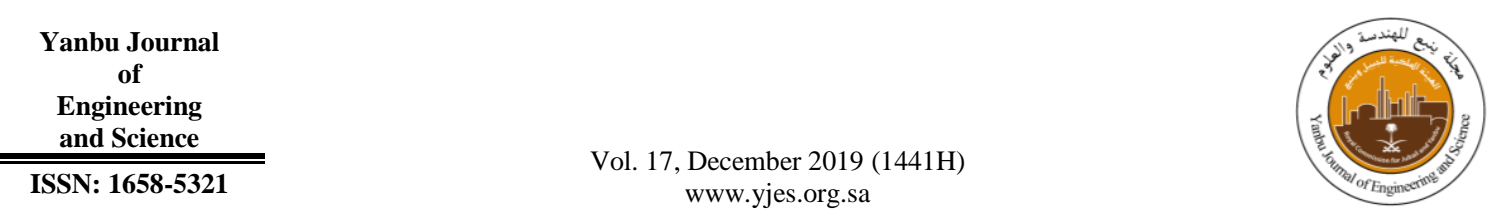

\title{
INTERNAL RESONANCE FOR POWER TRANSFORMER INTERACTED WITH CABLE TRANSIENTS
}

\author{
Alyaa A. Nassar, Abdel-Maksoud I. Taalab, Mohamed A. Izzularab, Nagy I. Elkalashy* \\ Electrical Engineering Department, Faculty of Engineering, Menofia University, 32511 \\ Shebin Elkom, Egypt. \\ E-mail: nagy.elkalashy@sh-eng.menofia.edu.eg
}

\begin{abstract}
Power transformers may be subjected to switching surges or fault events that may be responsible for internal transformer resonance. This paper deals with two scenarios of cable-transformer resonance. The first resonance case is due to single-phase earth fault, the second resonance is due to capacitor energization. These two situations lead to excessive transient overvoltages in the secondary side of the power transformer. The effect of various factors on these transient overvoltages is studied. The study is performed on three-phase 155 MVA power transformer. Fast Fourier transform is used for analysis and defining resonance frequencies. Also, phase-plane diagram and discrete wavelet transform are used for internal resonance feature extraction. The results confirm overvoltage occurrence on the low voltage side of power transformer behind cable due to cable-transformer resonance.
\end{abstract}

Keywords: Resonance, cable-transformer, instantaneous overvoltages

\section{INTRODUCTION}

Power transformers may suffer from dielectric failure as a result of high frequency transient overvoltages. These overvoltages encountered in electric power systems due to switching surges, fault events, atmospheric discharge or applying nonstandard terminal excitation voltage. These high frequency voltage surges may be below the surge arrestor protection level, so it won't be damped. Accordingly, it can arrive at the transformer terminals and transmits through the transformer windings. If the oscillating frequency of the external overvoltage surge is close to the resonance frequency of the transformer winding, internal transformer resonance occurs resulting in high frequency overvoltages with maximum value. Therefore, external transients occurring in power systems might trigger internal transformer resonance, which causes high frequency transient overvoltages leading to insulation breakdown for transformer winding [1-11]. Shunt capacitor banks are installed in high voltage and extra high voltage systems to achieve economic saving. These capacitors are being applied to increase power transfer capability, reduce equipment loading, reduce energy costs and control system voltage. Switching these capacitors causes transient voltages that may resonate the utility transformers [1, 12-13]. It has been reported in [12], that two specific transformer failure events due to capacitor bank energization some distance away from the transformers locations. Ground faults can be also responsible for transient overvoltage surges, which may be below the surge arrestor level. These surges injected to the transformer winding 
causing resonance overvoltages [1, 14-15]. An EHV transformer resonance overvoltage occurred as a result of single line to ground fault as reported in [14]. For this transmission system, the fault location has a great influence in the resonance overvoltage studies. The resonance overvoltages are higher when the transformer is open ended than when the transformer is terminated. In [16], it has been reported that internal transformer resonance can be also triggered by lightning surges for a distribution transformer. In [17], an analytical high frequency model for a wind farm transformer has been introduced. This model is suitable for studying transients in wind farms due to cable-transformer resonance. Internal transformer resonance due to earth fault and capacitor bank energization is reported in [1], where the effect of cable characteristic impedance and load conditions were considered. However, the effect of fault resistance, fault type and magnitude of capacitor were not considered. Furthermore, the frequency analyses were not comprehensively studied in that study. This paper focuses on the study of internal resonance situations for power transformer, where the ATP-EMTP program is used for the simulation study. Simulation is carried out for different power cable lengths and fault inception angles (the fault instant through the power frequency waveform). The corresponding resonance frequencies and resulted overvoltages are analyzed. Feature extraction of the resonance overvoltages is evaluated by using the phase-plane diagram and discrete wavelet transform (DWT).

\section{SIMULATED POWER SYSTEM}

The simulated cases are shown in Figure $1 \mathrm{a}, 1 \mathrm{~b}$ and Figure 2a, 2b, where the unloaded transformer is connected with the substation by a $120 \mathrm{kV}$ single core XLPE power cable.
The considered transformer is 155 MVA, $132 / 15 \mathrm{kV}, 50 \mathrm{~Hz}, \mathrm{Y} / \Delta$. The BCTRAN supporting routine of ATP is used to drive a linear representation of the three-phase studied transformer. Excitation and short circuit test data of this transformer are summarized in the Appendix. The linear part of the transformer model has been completed with adding the winding capacitances as external components. The winding capacitances of this transformer are considered $0.01 \mu \mathrm{F}, 0.005 \mu \mathrm{F}$ and 0.01 $\mu \mathrm{F}$ for primary to secondary, primary to ground and secondary to ground; respectively [18]. Three nonlinear Type-96 hysteresis inductors are added in a delta connection at the secondary side of the transformer ( $15 \mathrm{kV}$ terminals). These three hysteresis inductors represent the nonlinear magnetic core where their corresponding characteristics are in the Appendix. Frequency-based JMarti model is used for the underground power cable representation, which gives a frequency dependent model with constant transformation matrix based on the cable geometry and its material constants. The cable dimensions and parameters are defined in the Appendix. The corresponding ATPDraw circuit for both simulated cases are shown in Figure 2.
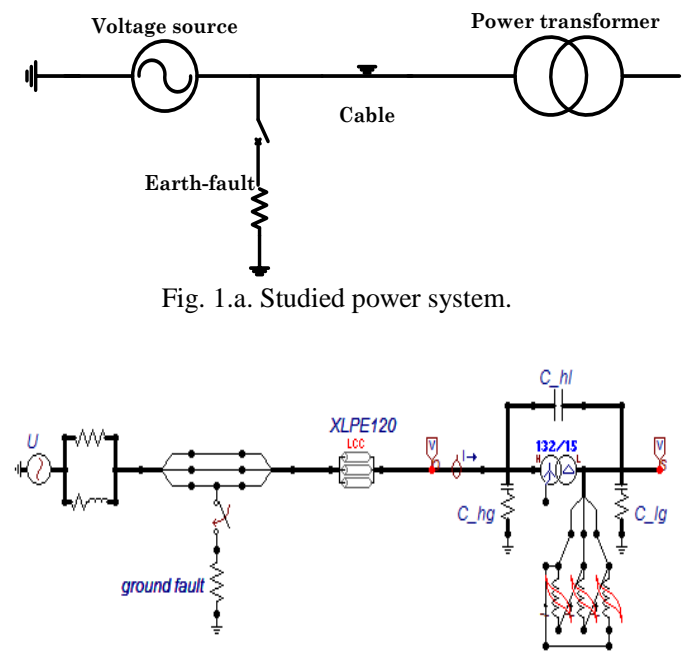

Fig 1.b. ATP Draw circuit for simulation. 


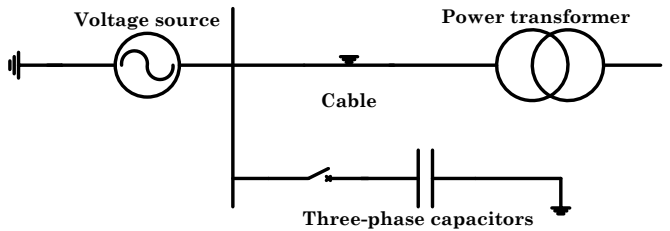

Fig.2.a. Studied power system.

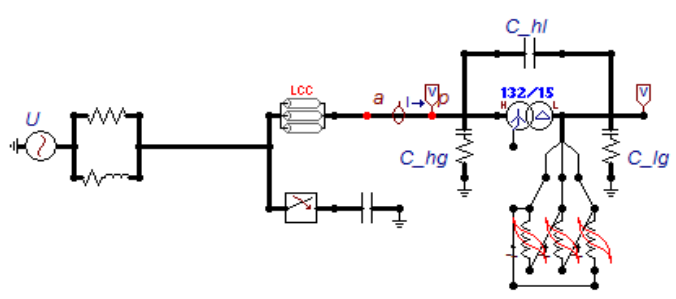

Fig.2.b. ATP Draw circuit for simulation.

\section{OVERVOLTAGES DUE TO EARTH FAULT}

The simulated system shown in Figure 1a and $1 \mathrm{~b}$ is used to evaluate the resonance occurrence resulted from an earth fault (single-phase fault type). The fault instant is assumed to be occurred at $0.02 \mathrm{~s}$, which corresponds to $300^{\circ}$ fault inception angle and the fault resistance is assumed $1 \mathrm{~m} \Omega$. Consequently, a voltage oscillation is generated over the power cable. For a 900 $\mathrm{m}$ cable length, the transient overvoltages due to phase-c earth fault are shown in Figure 3, where they are plotted at the transformer primary terminals. It can be seen that the transient oscillation frequency is very high in the faulted phase. However, the amplitude of this transient voltage is less than the system peak voltage. Accordingly, the overvoltage protection could not diminish these transients. The transients in the three-phase primary currents are depicted in Figure 4. This transient event in the transformer primary side triggers internal transformer resonance causing transient and steadystate overvoltages in the transformer secondary side as depicted from Figure 5.
Although the fault is in only single-phase in the primary side network, the resulted overvoltages are found in the three-phase at the transformer secondary side. The maximum instantaneous overvoltages are 68.9, 57.4 and $126.8 \mathrm{kV}$ (5.7, 4.8 and 10.6 p.u; respectively). After the transient period, there are steady-state overvoltages attained as 21.2, 21.7 and $15.2 \mathrm{kV}(1.76$, 1.8 and 1.27 p.u respectively). These values of the steady-state overvoltages are found to be the same for all assumed cable lengths. Figure 6 shows FFT analysis for phase-c secondary voltage. From the figure it can be observed that there is more than one resonance frequency, such as 48, 141 .. etc $\mathrm{kHz}$. The presence of these frequencies is the features that are to be detected in order to identify the internal resonance overvoltages.

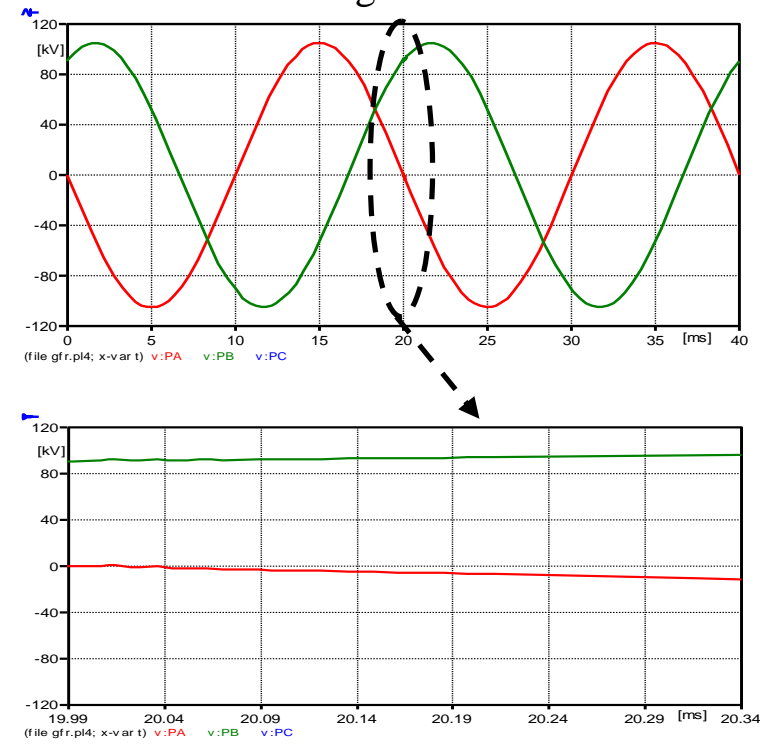

Fig. 3. The transformer primary side terminal voltage.

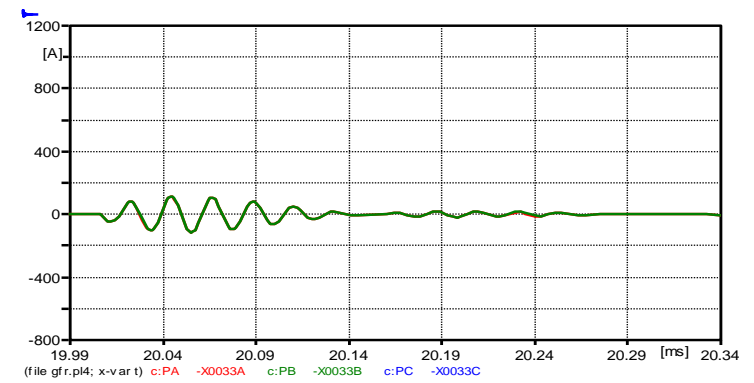

Fig. 4. The transformer zoomed primary current. 


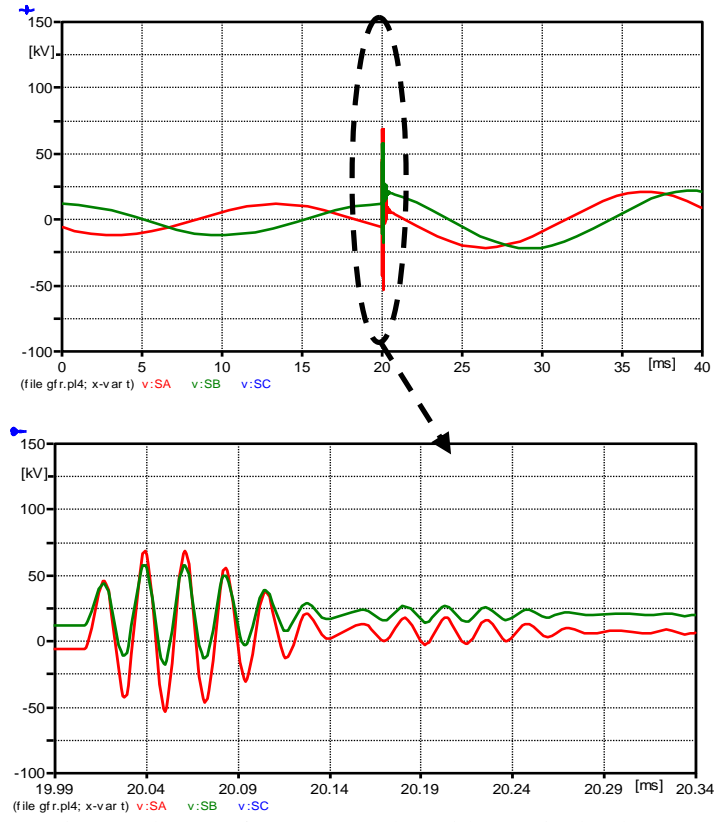

Fig. 5. The transformer secondary side terminal voltage.

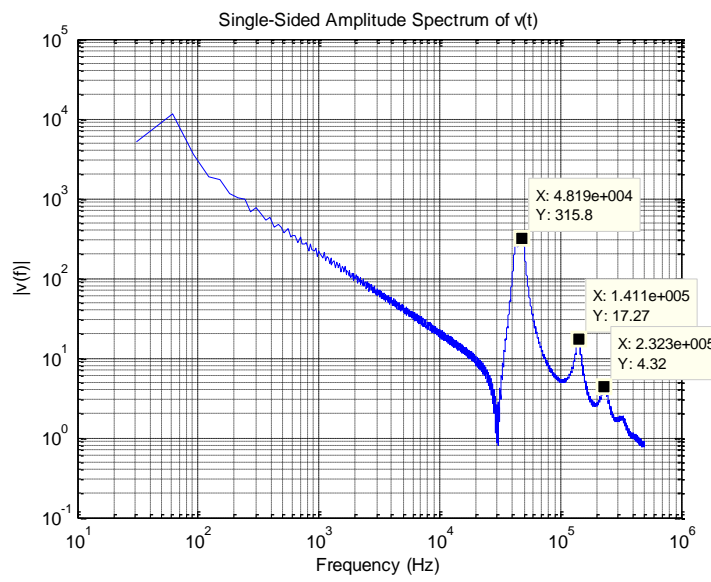

Fig. 6. FFT analysis for phase-c secondary voltage waveform.

\subsection{EFFECT OF CABLE LENGTH}

In order to study the effect of power cable length on the resonance transients, a simulation is conducted for different power cable lengths. Figure 7 shows the obtained maximum instantaneous overvoltage values for different power cable lengths. It is found that the instantaneous overvoltage values increase with increasing the power cable length till the length $900 \mathrm{~m}$ (critical length) and then the overvoltage start to decrease for longer power cable lengths. Note that this cable length can be found in the field in front of the transformer substation. For the $900 \mathrm{~m}$ cable length, its resonance frequency is matched with the transformer resonance frequency. This will be confirmed in section $\mathrm{V}$.

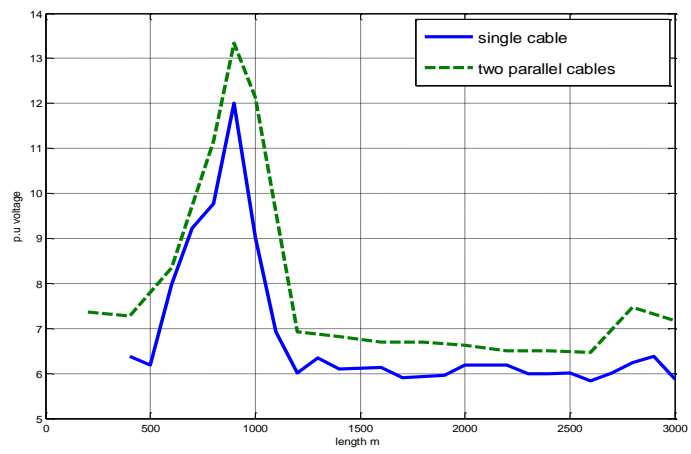

Fig. 7. Maximum instantaneous overvoltage for phase-c secondary against cable length.

Figure 7 shows also, the maximum instantaneous resonance overvoltage for different cable lengths concerning two parallel power cables (the green dashed line) instead of single cable. It is clear that in case of two parallel cables, the resonance overvoltage is higher than in case of single cable. As the equivalent characteristic impedance in case of two parallel cables is less than in case of single cable. However, the critical cable length is not changed for the two cases. Figure 8 compares between the FFT analysis of the transformer secondary voltage considering 900,1500 and $2500 \mathrm{~m}$ cable lengths. It is clear that there are more than one resonance frequency for each length, and the minimum resonance frequencies are 40, 28 and $17.2 \mathrm{kHz}$ for lengths 900, 1500 and $2500 \mathrm{~m}$; respectively. This is mean that the resonance frequency decreases with increasing the power cable length as depicted in Fig. 9. The interpretation of this behaviour of cable length effect can be easily done with the aid of travelling wave principles. When the fault occurs, a travelling surge travelled from the fault point toward the transformer primary side. As the transformer characteristic impedance is higher than that of the cable, the reflection coefficient will be positive. However, at the fault point, the reflection is negative due to solid fault status. Accordingly, there is a travelling wave 
over the cable at resonance frequency which is a function of the cable length. Approximately, the resonance frequency is the quarter of cable travelling speed divided by the fault distance to the transformer connection [14]. Accordingly, the cable length (or the fault distance) affects the resonance frequency of the wave.

\subsection{EFFECT OF FAULT INCEPTION ANGLE}

Figure 10 shows the three-phase secondary voltages for power cable length $900 \mathrm{~m}$ and fault inception angle $180^{\circ}$ that is at zero crossing voltage instant. Accordingly, the instantaneous transient overvoltage is very low. However; there are steady-state overvoltages in the three-phases. Figure 11 shows the change in the instantaneous overvoltage for the transformer secondary terminals against the fault inception angle. As it is well-known, the maximum instantaneous overvoltages occur for fault inception angles $90^{\circ}$ and $270^{\circ}$. On the other hand, there are no instantaneous overvoltages for angles $0^{\circ}, 180^{\circ}$ and $360^{\circ}$ that are at the zero crossing of the faulty phase voltage. Also, the detected resonance frequencies are not affected by the change of the fault inception angle as shown in Figure 12.

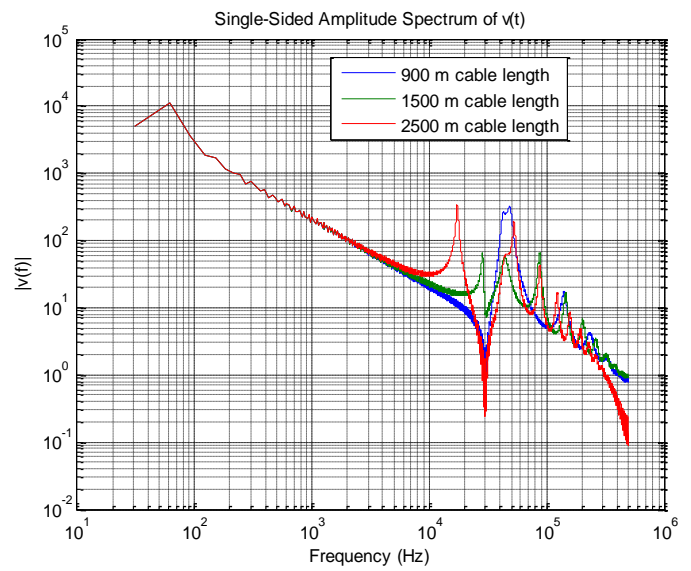

Fig. 8. FFT analysis for phase-c secondary voltage for different lengths.

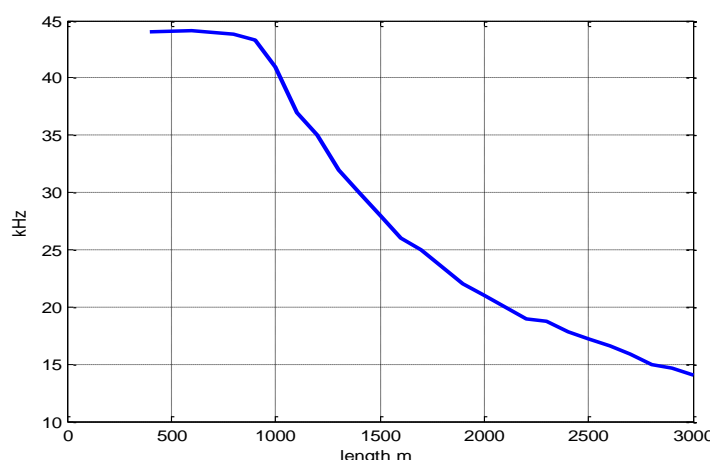

Fig. 9. Minimum resonance frequency for phase-c secondary to the base of cable length.

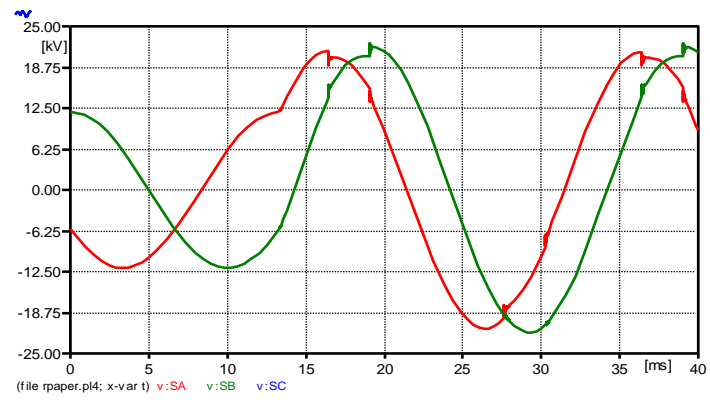

Fig. 10. The transformer secondary terminal voltages for fault inception angle $180^{\circ}$

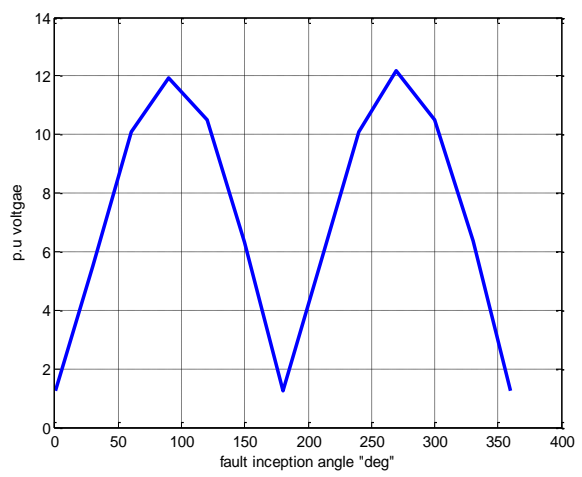

Fig. 11. Instantaneous voltage for phase-c secondary to the base of fault inception angle.

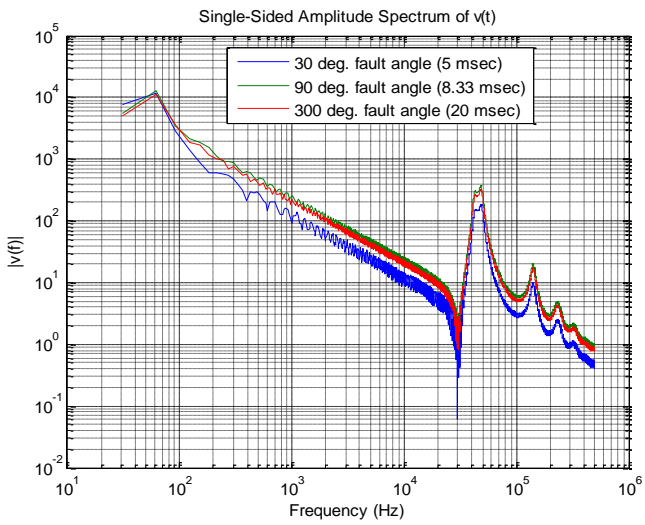

Fig. 12. FFT analysis for phase-c secondary voltage for different fault inception angles. 


\subsection{EFFECT OF FAULt RESISTANCE}

For the aforementioned test cases, the fault resistance is assumed $1 \mathrm{~m} \Omega$. Figure 13 shows the maximum instantaneous overvoltages to the base of the fault resistance, when it is increased from $1 \mathrm{~m} \Omega$ to $50 \Omega$ and the cable length is assumed to be $900 \mathrm{~m}$ and the fault inception angle is $300^{\circ}$. As expected, increasing the fault resistance can limit the resonance overvoltages. Figure 14 shows the FFT analysis for the secondary voltage waveform for the assumed $1 \mathrm{~m} \Omega$ and $50 \Omega$ fault resistances. The frequency spectrum magnitude is affected by the fault resistance as the high frequencies are diminished. However, a resonance peak occurs at $48 \mathrm{kHz}$.

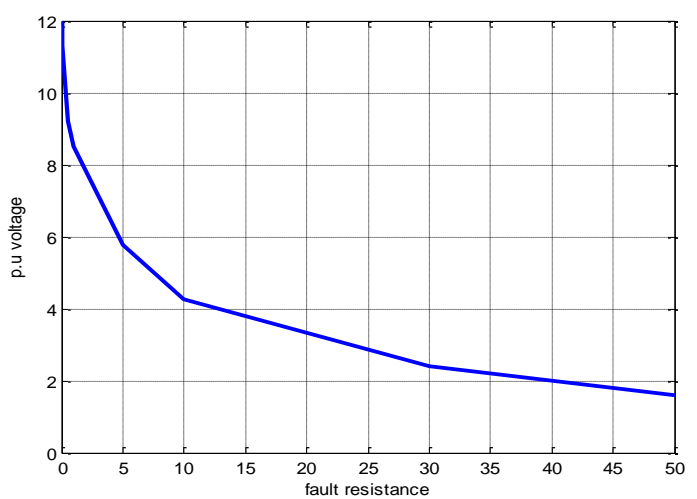

Fig. 13. Maximum instantaneous voltage for phase-c secondary to the base of fault resistance.

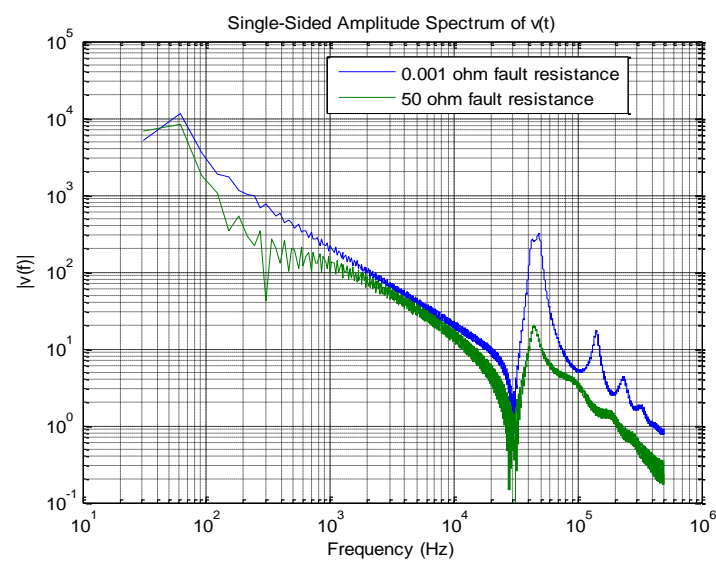

Fig. 14. FFT analysis for phase-c secondary terminal voltage waveform.

\subsection{EFFECT OF FAULt TyPe}

In the previous subsections, the earth fault was considered. However in this subsection, the resonance due to phase faults will be evaluated. Considering the system under study shown in Figure 1, a phase fault of phase-b to $c$ to earth is assumed to occur at the instant $20 \mathrm{~ms}$, corresponding to $60^{\circ}$ and $300^{\circ}$ fault inception angles for phase-b and c; respectively. Figure 15 shows the primary side voltages, when a power cable length of $900 \mathrm{~m}$ is assumed. Referring to that figure it can be shown that there are instantaneous overvoltages in the two faulty phases. Their corresponding zoomed primary currents are shown in Figure 16. As in the previous case (single-phase earth fault), there are instantaneous and steadystate overvoltages in the transformer secondary side as shown in Figure 17. The peak value of instantaneous overvoltages are $1.86,11.35$ and 13.1 p.u and the steady-state overvoltages are 1.76, 1.8 and 1.26 p.u; respectively. Comparing these overvoltage values with those in case of single-phase to earth fault shown in Figure 5 , the instantaneous overvoltage values are higher in this case however, the steadystate overvoltage values are lower.

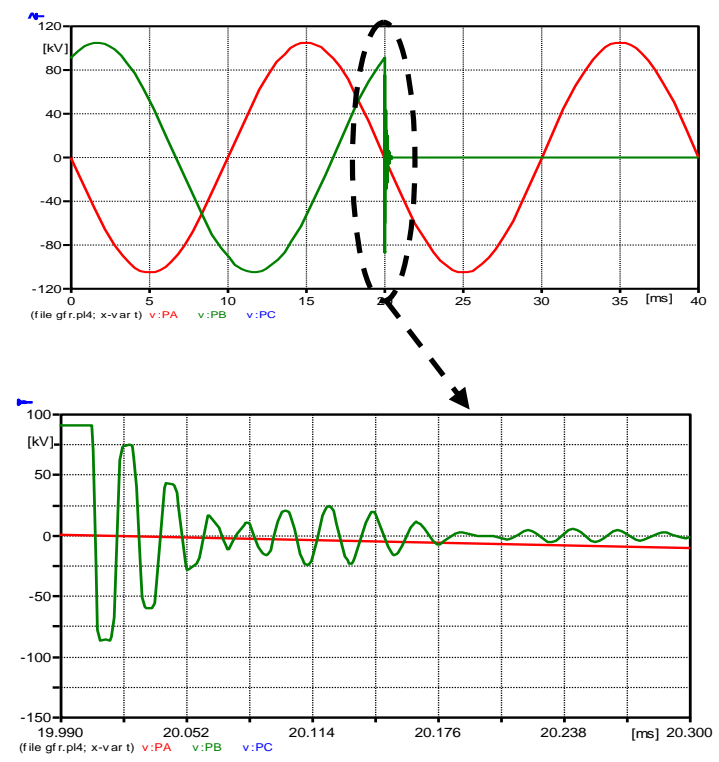

Fig. 15. The transformer primary side terminal voltage. 


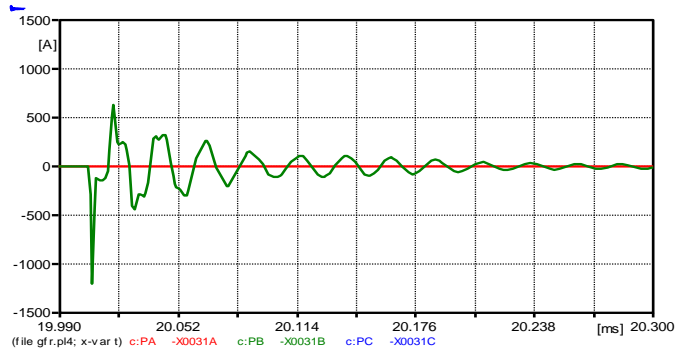

Fig. 16. The transformer zoomed primary current.
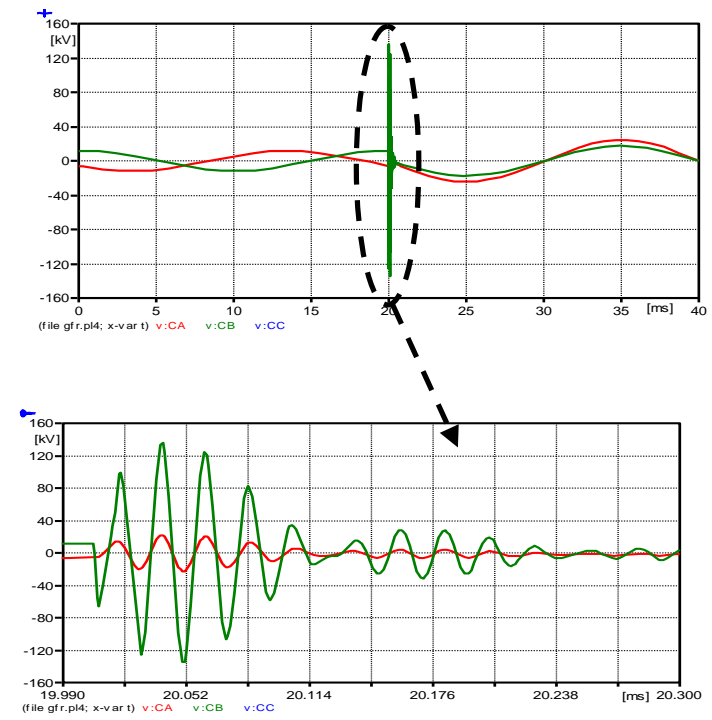

Fig. 17. The transformer secondary side terminal voltage.

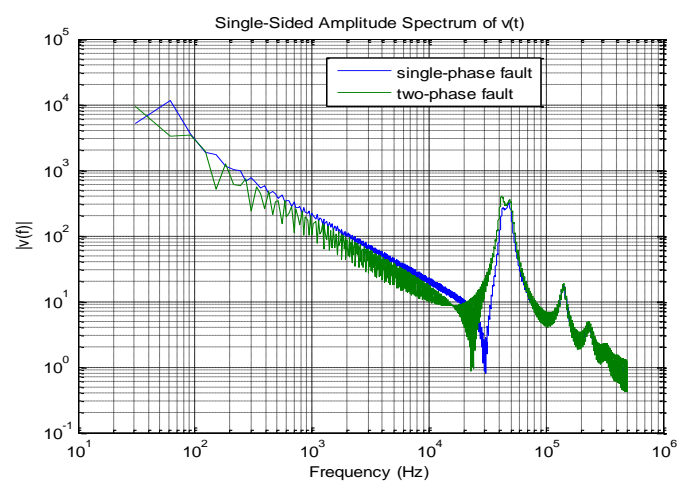

Fig. 18. FFT analysis for phase-c secondary voltage waveform.

The FFT analysis for secondary side voltage for both assumed fault cases is shown in Fig. 18, which shows that the same high frequencies attained for both fault types. These results confirm that not only the earth fault produces resonance overvoltages.

\section{OVERVOLTAGES DUE TO CAPACITOR BANK ENERGIZATION}

In the previous section, the study was carried out for the resonance overvoltages, which occur due to faults in the power cable feeding an unloaded transformer. In this section, the studied resonance case is resulted from a sudden connection of a capacitor bank with an underground feeding power cable, as shown in Figure 2. For this considered system, the power transformer is fed through a $120 \mathrm{kV}$ underground power cable. Energizing the capacitor bank suddenly chops the voltage waveform as shown in Figure 19. Consequently, a voltage oscillation over the feeding power cable is created, which resulted in transient overvoltages at the transformer primary side as shown in Fig. 20. The waveform distortion in the capacitor busbar voltage is due to energizing a three-phase $50 \mu \mathrm{F}$ capacitor at $8.333 \mathrm{~ms}$ that corresponds to $90^{\circ}$ switching inception angle for phase-c and $900 \mathrm{~m}$ feeding cable. At the switching instant, the three-phase voltages are reduced to zero simultaneously as depicted in Figure 19. As shown in Figure 20, this disturbance causes a high frequency transient overvoltage at the transformer primary side. The corresponding high voltage side currents are obvious in Figure 21 showing instantaneous and steady-state overcurrents. Therefore, internal transformer resonance is triggered as depicted from Figure 22, which gives instantaneous overvoltages for the threephase secondary side voltage waveforms. This overvoltage reaches 15.8 p.u for phase-c. FFT analysis for the same phase is shown in Figure 23, which shows high resonance frequencies $50,140,236 \ldots$ $\mathrm{kHz}$. Also there are lower frequencies 127 and $279 \mathrm{~Hz}$, which corresponds to inserting the capacitor into the network. 


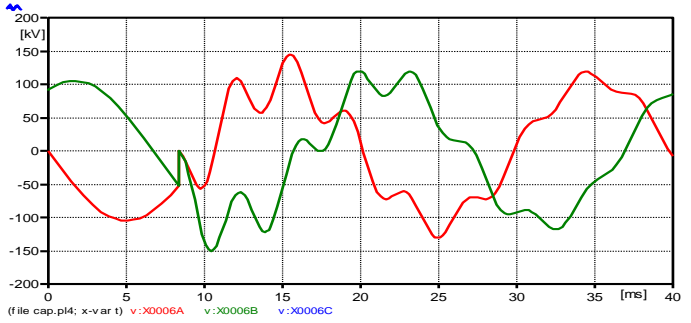

Fig. 19. Feeding cable sending end voltage.

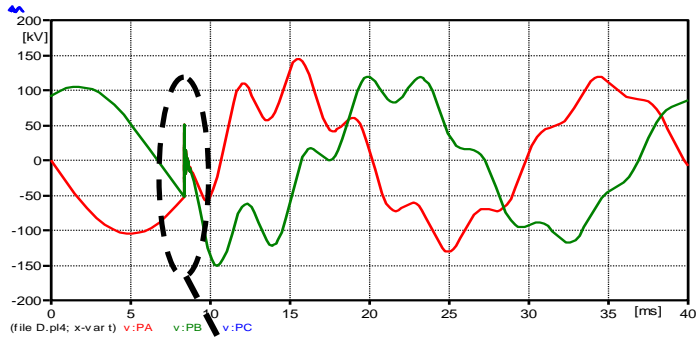

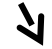

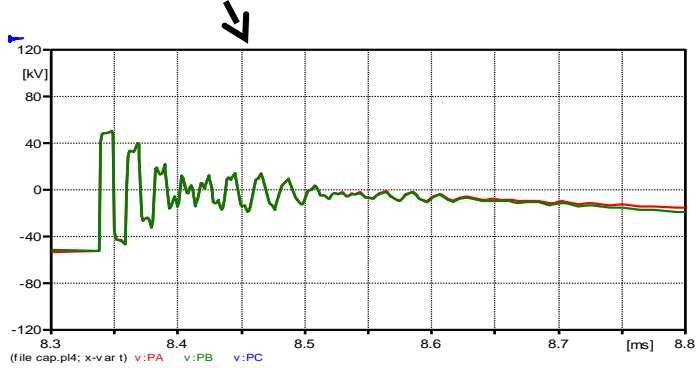

Fig. 20. Primary side overvoltage.

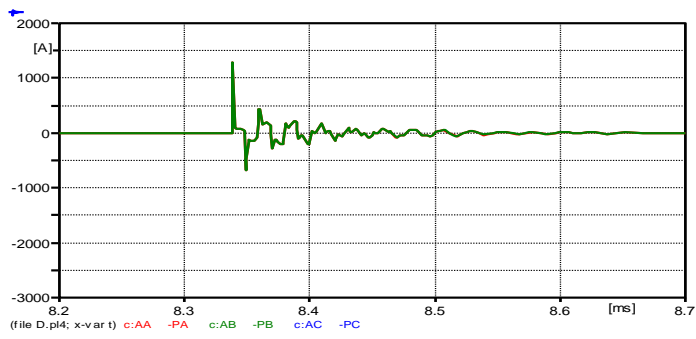

Fig. 21. Zoomed primary side current.

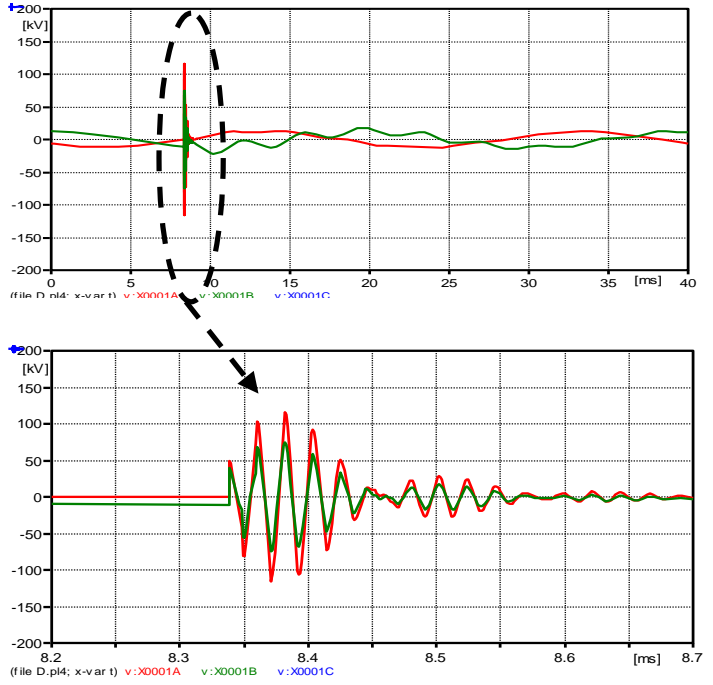

Fig. 22. Secondary side overvoltage.

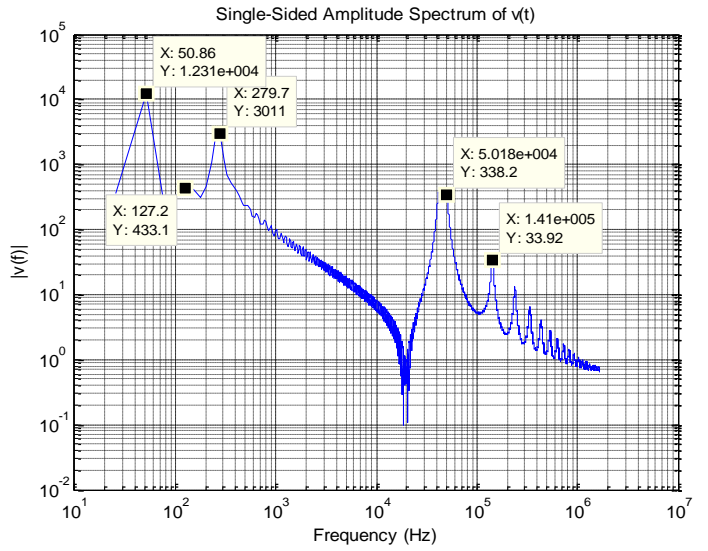

Fig. 23. FFT analysis for phase-c secondary voltage waveform.

\subsection{EFFeCt OF CABLE Length AND SWITCHING ANGLE}

In order to study the effect of power cable length, a $50 \mu \mathrm{F}$ capacitor is energized at $0.1 \mathrm{~ms}\left(120^{\circ}\right.$ for phase-c) with various feeding power cable lengths. Figure 24 shows the variations in the transformer secondary side for the maximum peak instantaneous overvoltage due to resonance to the base of cable length. The same critical length is attained $900 \mathrm{~m}$ corresponding to the highest value for resonance instantaneous overvoltage. However, there is another obvious resonance found at length $2.8 \mathrm{~km}$. It is found that the power cable length has an influence on the resonance frequency as depicted in Figure 25. From which it can be seen that the minimum resonance frequency for lengths $0.9,2$ and $2.8 \mathrm{~km}$ are $41.9,21.5$ and $15.6 \mathrm{kHz}$; respectively. It is clear that the minimum resonance frequency is decreased with increasing the power cable length. The frequencies 127 and $279 \mathrm{~Hz}$ are still found in all test cases shown in Figure 25 regardless the assumed cable length. As previously revealed, they are due to the capacitor transients. When the simulation is done for a capacitor of 50 $\mu \mathrm{F}$ switched at different switching inception angles, the same conclusion of inception angle effect is attained. The transient overvoltage reaches its maximum magnitude for switching angles $90^{\circ}$ and 
$270^{\circ}$. It is also found that, the resonance frequencies aren't affected by the switching angle.

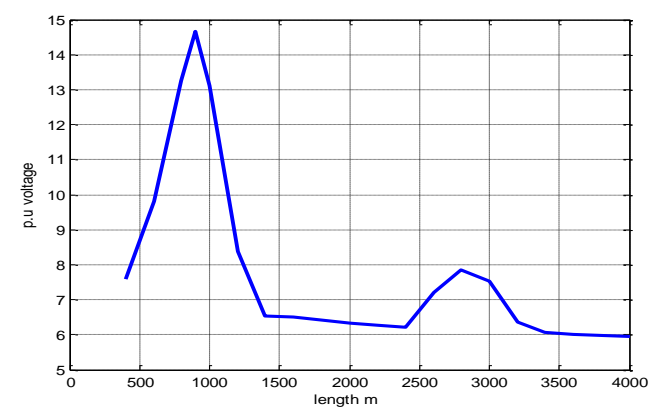

Fig. 24. Maximum instantaneous overvoltage for phase-c secondary to the base of cable length.

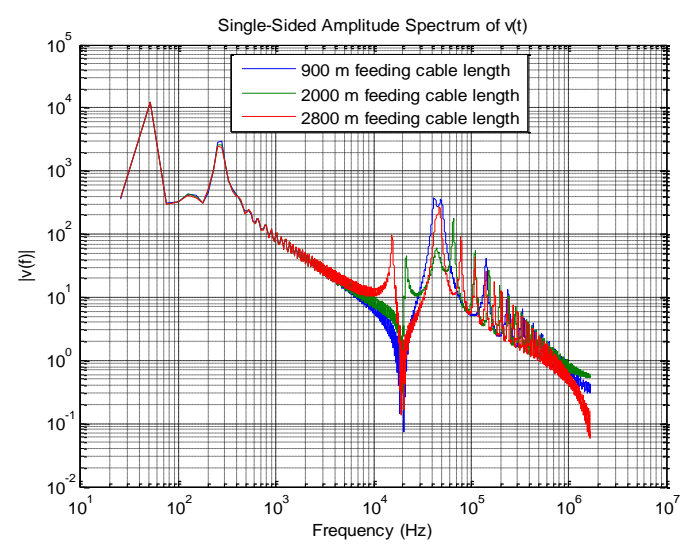

Fig. 25. FFT analysis for phase-c secondary for different cable lengths.

\subsection{EFFECT OF CAPACITOR SIZE AND SWITCHING SEQUENCE}

Comparing energizing capacitors of $10 \mathrm{mF}$ and $50 \mu \mathrm{F}$ at switching inception angle $90^{\circ}$ for phase-c, the instantaneous overvoltges are the same during the transient period. However, the lower frequency overvoltage decreases with increasing the capacitance value as confirmed by the frequency spectrum shown in Figure 26. For high frequencies, both the magnitude of the instantaneous overvoltage and the resonance frequencies during the transient period aren't affected by the capacitor size. Figure 27 to 29 show the performance when the three capacitors are switched arbitrary considering $1 \mathrm{~ms}$ lagging time between each phase. The scenario is that the phase-a capacitor is switched at 6.33 ms (294 switching inception angle), phase-b capacitor is switched at $7.33 \mathrm{~ms}$ $\left(192^{\circ}\right.$ switching inception angle) and phase-c capacitor is switched at $8.33 \mathrm{~ms}$ $\left(90^{\circ}\right.$ switching inception angle). Figure 27 and 28 show that internal resonance is triggered for each connected capacitor, resulting in instantaneous and steady-state overvoltages in the three-phase secondary voltage. The maximum peak for these instantaneous overvoltages are $12.3 \mathrm{p} . \mathrm{u}$ after switching phase-a, 3 p.u after switching phase-b also and 13 p.u after switching the last phase-c. Note that these values are different due to different switching inception angle for each phase. Figure 29 shows that the high resonance frequencies are the same for each phase; however, the resonance overvoltage amplitudes for the three-phases are different.

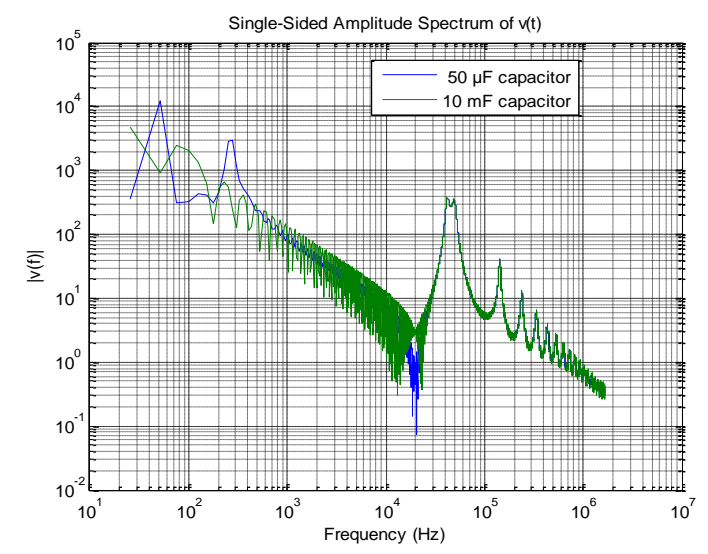

Fig. 26. Effect of capacitor magnitude on the FFT analysis for phase-c secondary.

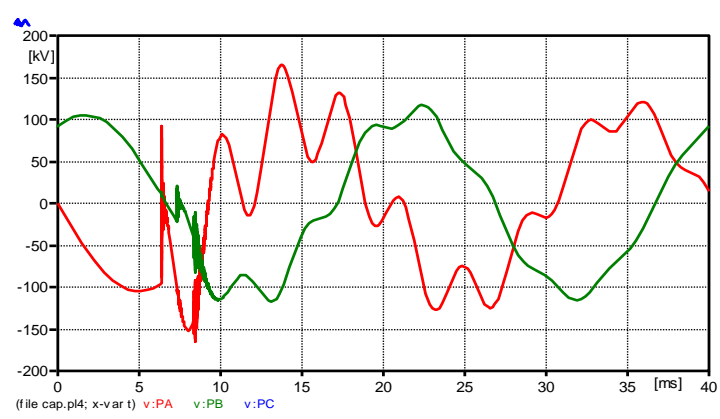

Fig. 27. Primary side voltages. 


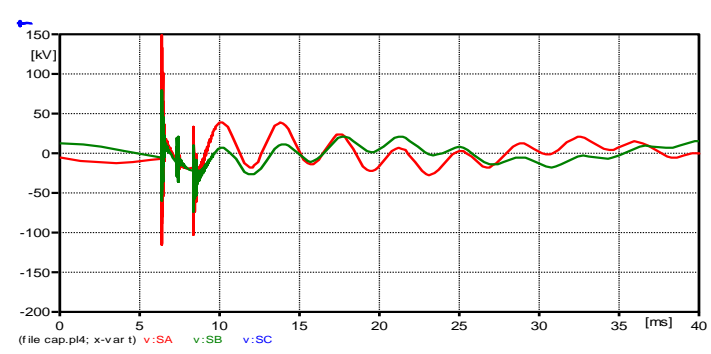

Fig. 28. Secondary side voltages.

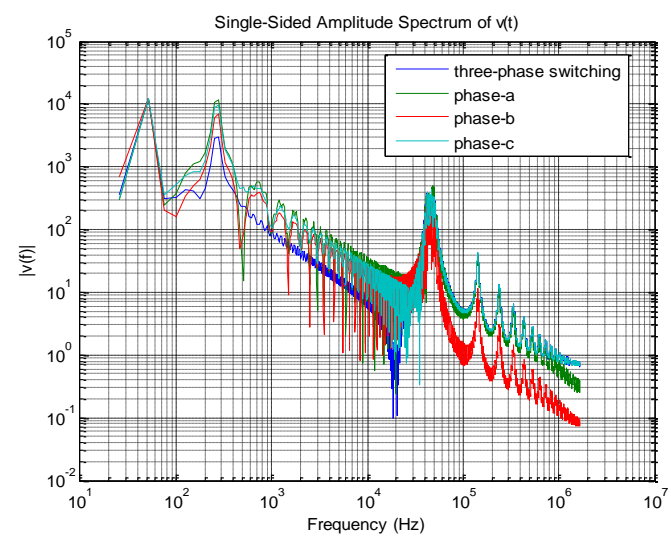

Fig. 29. FFT analysis for secondary side voltages.

\section{RESONANCE FREQUENCY OVERVOLTAGE OF CABLE- TRANSFORMER IDENTIFICATION}

In order to illustrate the resonance results discussed in the previous sections, the frequency response of the considered transformer and the feeding power cables should be evaluated. An induced voltage of $450 \mathrm{~V}, 0.87 / 50 \mu \mathrm{s}$ impulse waveform shown in Fig. 31 is used to determine the frequency response for both the power transformer and the power cable. Figure 32 shows the frequency response characteristics of the considered 155 MVA power transformer resulted from application of the impulse voltage at the transformer primary terminals. It is depicted that the transformer resonance frequency is about $47 \mathrm{kHz}$, i.e. if the transformer is excited with any surge that has this resonance frequency, internal transformer resonance will be triggered resulting in maximum value of overvoltage at the secondary terminals. In order to determine the power cable frequency response characteristics, its sending end is fed with a $450 \mathrm{~V}, 0.87 / 50 \mu$ s lightning impulse voltage. The receiving end frequency response characteristics for the power cable is given in Figure 32, which shows that there are more than one resonance frequency. The first resonance frequency of the $900 \mathrm{~m}$ power cable is about $49 \mathrm{kHz}$, which closely matches with the transformer resonance frequency, resulting in the highest overvoltage as previously shown in Figure 7 and 24.

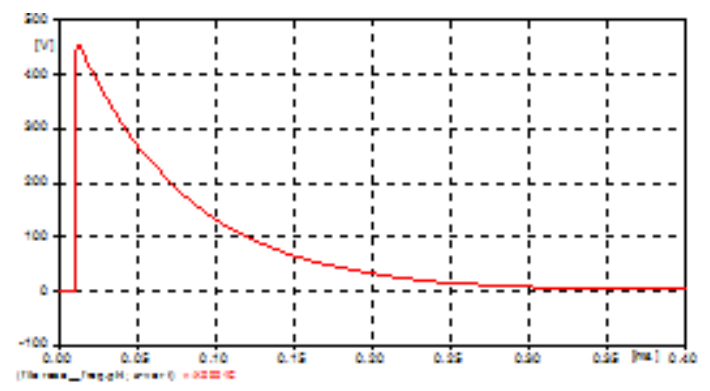

Fig. 30. Lightning impulse voltage waveform.

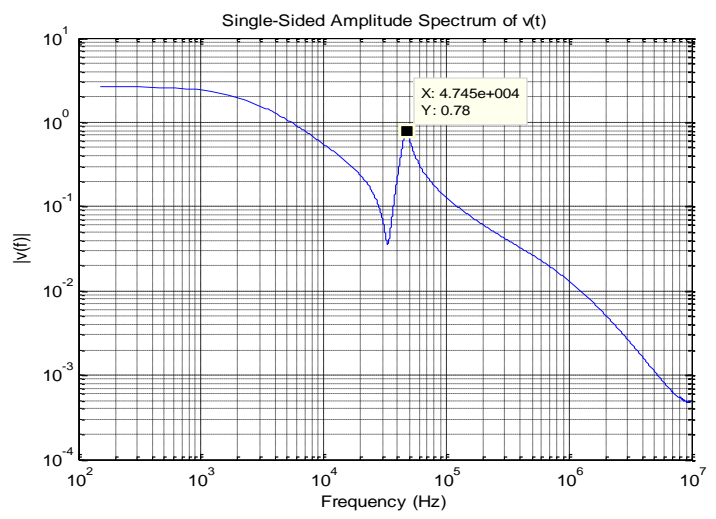

Fig. 31. Frequency response characteristics of the power transformer.

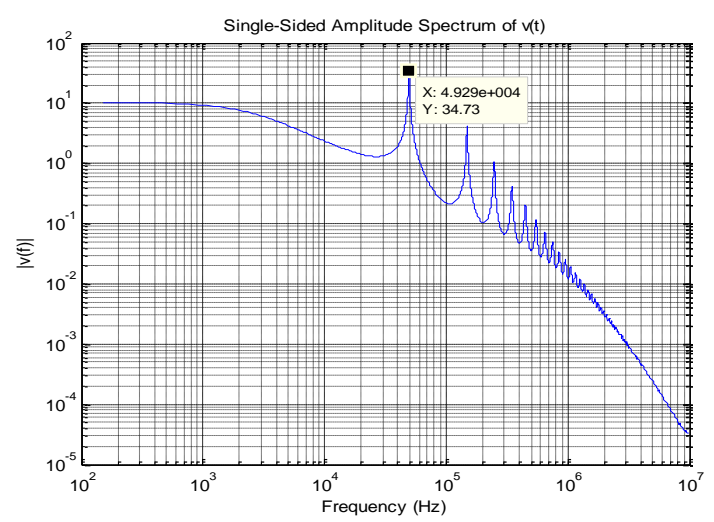

Fig. 32. Frequency response characteristics of the $900 \mathrm{~m}$ power cable. 


\section{RESONANCE OVERVOLTAGE FEATURES EXTRACTION}

In the previous sections, overvoltages due to cable-transformer resonance are studied. In this section, the features of these overvoltages are extracted using the phaseplane diagram and discrete wavelet transform (DWT). Figure 33 and 34 show the resonance features due to earth fault for the studied power transformer. Figure 33 show the phase-plane diagram under resonance due to phase-c to earth fault. It is clear that, the operating loops due to the resonance (during the transient period) has much lower flux amplitudes than that for the normal operation loop; however higher overvoltages are attained. Also, DWT details for theses resonance secondary voltages are shown in Figure 34, where $\mathrm{db} 5$ is used as a mother wavelet and 2 $\mathrm{MHz}$ sampling frequency. The maximum amplitude is localized in detail D5 that includes frequencies 43 and $48 \mathrm{kHz}$. Note that these frequencies are the resonance frequencies previously extracted by FFT as in Figure 6 for this case. The features extracted using the FFT, phase-plane diagram and DWT can be exploited for internal resonance detection.

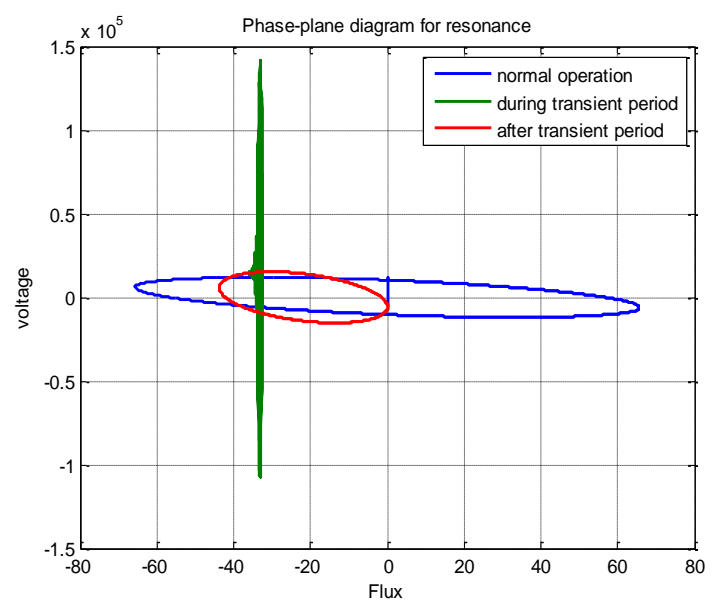

Fig. 33. Phase-plane diagram ( $\phi$-v) for phase-c secondary due to resonance for the studied power transformer.
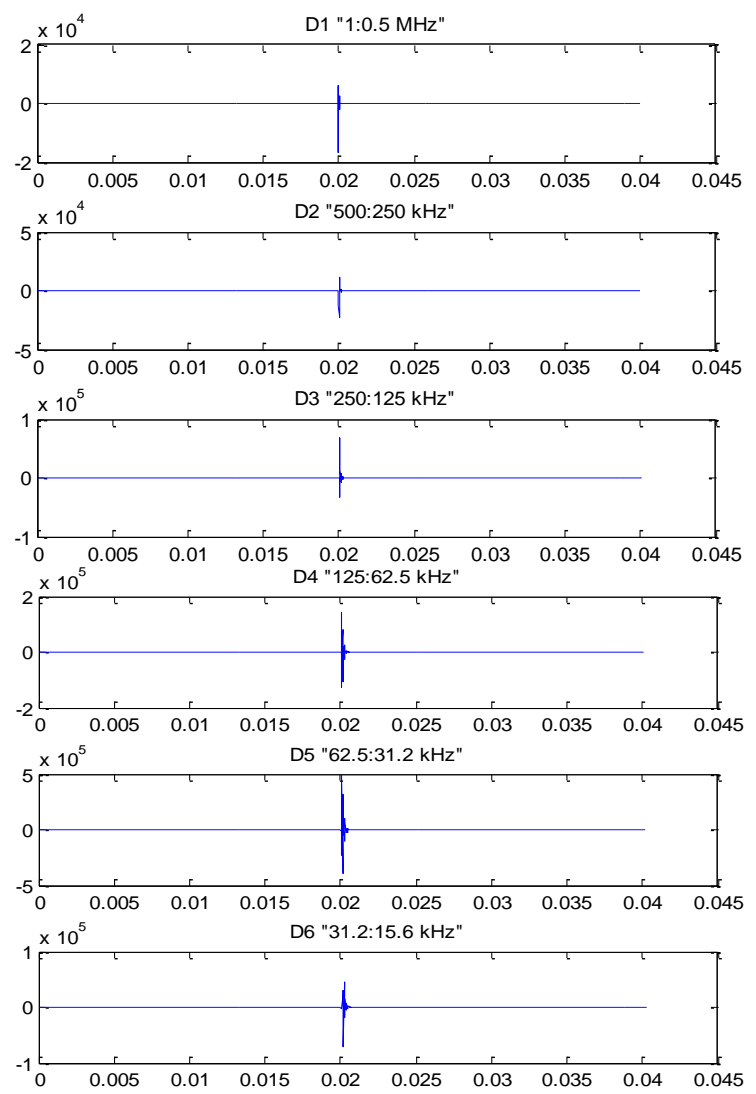

Fig. 34. DWT analysis for phase-c secondary voltage due to resonance for the studied power transformer.

\section{CONCLUSION}

Cable-transformer resonance has been studied for a 155 MVA unloaded power transformers. This transformer is fed through an underground power cable. It has been depicted that excessive transient overvoltages can be obtained in the transformer secondary side due to the transformer internal resonance. These transient overvoltage values can reach to $15 \mathrm{p} . \mathrm{u}$ for this studied case. It is found also that, there are sustained overvoltages after the transient period that reached 1.8 p.u for both studied resonance cases. It is found that both the resonance frequency and the instantaneous overvoltage are greatly affected by the power cable length for both studied resonance cases. Therefore, the critical cable length should be known for any system that has a probability of resonance occurrence, in order to avoid the resulted maximum overvoltages. However, 
earth faults can occur at different fault distances over the cable. Therefore, the overvoltage protection cannot be ignored at the transformer secondary side. For the note, the earth fault over a long overhead line can produce the oscillation resonating with the power transformer. The simulation verification has been conducted for the overhead line-transformer resonance; however, the results are not shown. It is depicted that switching the capacitors at the zero crossing of the voltage waveform can limit the transient overvoltages due to resonance. However it is difficult to control the fault inception angle. If there are mitigation methods for transient overvoltages due to switching, their application cannot be considered with the fault based-resonance overvoltages. An overvoltage protection such as surge arrestor should be installed at the secondary side of the transformer. This is to only mitigate the induced overvoltage at the secondary side.

\section{APPENDIX}

Excitation and short circuit test data for the studied transformer is summarized in Table 1. Figure 35 shows the magnetizing characteristics (flux-current characteristics) for the transformer core.

TABLE 1: THE NAME-PLATE DATA OF THE SIMULATED POWER TRANSFORMER

\begin{tabular}{|c|c|}
\hline Voltage rating Vhigh/Vlow & $132 / 15 \mathrm{kV}$ \\
\hline Frequency & $50 \mathrm{~Hz}$ \\
\hline Power rating & $155 \mathrm{MVA}$ \\
\hline Winding connection & $\mathrm{Y} / \mathrm{d} 11$ \\
\hline Excitation current & $0.3 \% / 2.67 \mathrm{~A}$ \\
\hline Excitation losses & $74 \mathrm{~kW}$ \\
\hline Short circuit losses & $461 \mathrm{~kW}$ \\
\hline Short circuit reactance & $14 \%$ \\
\hline
\end{tabular}

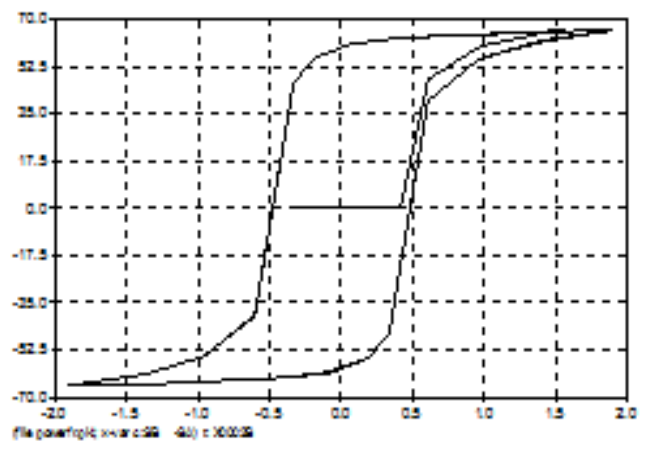

Fig. 35. Hysteresis characteristics for transformer core.

TABLE 2: POWER CABLES PARAMETERS

\begin{tabular}{|c|c|}
\hline Rated voltage for the power cable & $120 \mathrm{kV}$ \\
\hline Cross section of conductor $\left(\mathrm{mm}^{2}\right)$ & 1200 \\
\hline Diameter of conductor $(\mathrm{mm})$ & 42.8 \\
\hline Insulation thickness $(\mathrm{mm})$ & 13 \\
\hline Diameter over insulation $(\mathrm{mm})$ & 73.8 \\
\hline Outer diameter of cable (mm) & 89.5 \\
\hline Conductor resistivity $(\Omega . \mathrm{m})$ & $2.3 \times 10^{-8}$ \\
\hline Ground resistivity $(\Omega)$ & 20 \\
\hline Relative permeability of the conductor material & 1 \\
\hline $\begin{array}{c}\text { Relative permeability of the insulating material } \\
\text { outside the conductor }\end{array}$ & 2.7 \\
\hline $\begin{array}{c}\text { Relative permittivity of the insulating material } \\
\text { outside the conductor }\end{array}$ & 1 \\
\hline
\end{tabular}

\section{REFERENCES}

[1] B. Gustavsen "Study of Transformer Resonant Overvoltages Caused by Cable-Transformer High-Frequency Interaction" IEEE Transactions on Power Delivery, Vol. 25, No. 2, April 2010, pp. 770-779.

[2] A. K. Lokhanin (Date 2013, January) "The Resonance Overvoltages in Power Transformer" Moscow Russia. [Online]. Available: http://a2.cigre.org.

[3] S. Pramanik, S.Anees and L.Satish "Interleaved Winding and Suppression of Natural Frequencies" IET Electric Power Application, 2013, Vol. 7, Iss. 4, pp. 237-244.

[4] M. Florkowski, J. Furgal and P. Pajak "Analysis of Fast Transient Voltage Distributions in Transformer Windings under Different Insulation Conditions" IEEE Transactions on Dielectrics and Electrical 
Insulation, Vol. 19, No. 6, December 2012, pp. 1991-1998.

[5] M. Florkowski, J. Furgal "Transfer Function Based Recognition of Resonance Overvoltages in Transformer Windings" Int. Conf. on High Voltage Engineering and Application, Chongqing, China, November 913, 2008, pp. 12-15.

[6] M. Popov, L. van der Sluis, G. C. Paap, and H. de Herdt "Computation of Very Fast Transient Overvoltages in Transformer Windings" Int. Conf. on Power Systems Transients, (IPST05), Montreal, Canada, June 19-23, 2005.

[7] M. Florkowski, J. Furgal and P. Pajak "Frequency Method for Identification of Resonance Overvoltages in Transformer Windings" Int. Conf. on Solid Dielectrics, Potsdam, Germany, July 4-9, 2010, pp. 1-4.

[8] P. Mitra, A. De and A. Chakrabarti "Resonant Behavior of EHV Transformer Windings under System Originated Oscillatory Transient Overvoltages" Journal on Electrical Power and Energy Systems, Vol. 33, Iss. 10, December 2011, pp. 1760-1766.

[9] A. De, D. Debhnath and A. Chakrabarti "A Study of the Impact of Low-Amplitude Oscillatory Switching Transients on Grid Connected EHV Transformer Winding in a Longitudinal power Supply" IEEE Transactions on Power Delivery, Vol. 24, No. 2, April 2009, pp. 679-686.

[10] P. Mitra, A. De and A. Chakrabarti "Response of EHV Transformers to Systems-Originated Oscillatory Switching Transients" IEEE Transactions on Power Delivery, Vol. 27, No. 1, January 2012, pp. 224-235.

[11] M. Popov and L. van der Sluis "Improved Calculations for No-Load Transformer Switching Surges" IEEE Transactions on Power Delivery, Vol. 16, No. 3, July 2001, pp. 401-408.
[12] R.S. Bayless, J.D. Selman, D.E. Truax and W. E. Reid "Capacitor Switching and Transformer Transients" IEEE Transactions on Power Delivery, Vol. 3, No. 1, January 1988, pp. 349-357.

[13] D. Debnath, A. De, A. Chakrabarti and D.P. Kothari "Studies on the Impact of Capacitor Bank Switching on Grid Connected Transformers" Journal on Electrical Power and Energy Systems, Vol. 43, Iss. 1, December 2012, pp. 126-130.

[14] J. A. Halladay and C. H. Shih "Resonant Overvoltage Phenomena Caused by Transmission Line Faults" IEEE Transactions on Power Apparatus and Systems, Vol. PAS104, Iss. 9, September 1985, pp. 2531-2539.

[15] R. J. Musil, G. Preininger, E. Schopper, and S. Wenger "The Resonance Effect of Oscillating System Overvoltages on Transformer Windings" IEEE, Power Engineering Review, Vol. PER-2, Iss. 10, October 1982, pp. 29-30.

[16] M. Hori, M. Nishioka, Y. Ikeda, K. Noguchi and K. Kajimura "Internal Winding Failure Due to Resonance Overvoltage in Distribution Transformer Caused by Winter Lightning" IEEE Transactions on Power Delivery, Vol. 21, No. 3, July 2006, pp. 1600-1606.

[17] A.H. Soloot, H.K. Høidalen and B. Gustavsen "Modeling of Wind Turbine Transformers for the Analysis of Resonant Overvoltages" Journal on Electric Power Systems Research, 2014, pp. 1-9. Available: http://dx.doi.org/10.1016/j.epsr.2014.03.004

[18] ATPDRAW version 3.5 for Windows 9x/NT/2000/XP Users' Manual. 